\title{
The effect of azathioprine on gastric mucosal histology and acid secretion in chronic gastritis
}

\author{
A. D. JORGE AND D. SANCHEZ
}

From the Departments of Gastroenterology, Faculty of Medical Science, U.N. Cuye, and Gastroenterology Service, Spanish Hospital of Mendoza, Mendoza, Argentina

SUMMARY Fourteen patients were selected with advanced superficial chronic gastritis (grade II), marked chronic gastritis with partial atrophy (grade III), or chronic gastritis with total atrophy in which intestinal metaplasia was observed (grade IV). Azathioprine was administrated to all of them for periods varying from two and a half to six months. There were no side effects except in one patient, in whom nausea and vomiting made it necessary to remove him from the trial.

Acid output in these 14 patients showed an average change which was statistically significant.

Statistical analysis of the sample as a whole shows that, with a 0.95 probability improvement could be expected in 37 to $85 \%$ of the patients given azathioprine.

The aetiology of chronic gastritis is unknown, but autoimmune factors have been suggested (Hennes, Sevellius, Llewellyn, Woods, Joel, and Wolf, 1960; Fisher, Rees, and Taylor 1965; Irvine, 1965; Fisher, Mackay, Taylor, and Ungar, 1967; Hausamen, Halcrow, and Taylor, 1969; Glass, 1970). Corticosteroids may improve the mucosal abnormalities of patients with chronic gastritis as well as restore and increase the secretion of acid and intrinsic factor (Doig, Girdwood, Duthie, and Knox, 1957; Kristensen and Friis, 1960; Kristensen and Friis, 1962; Ardeman and Chanarin, 1965; Jeffries, Todd, and Sleisenger, 1966). We have therefore studied the effects of another immunosuppressant drug, azathioprine, on patients with chronic gastritis.

\section{Material and Methods}

Azathioprine was given to five men and nine women, whose ages ranged from 27 to 71 years, with the histological diagnosis of chronic gastritis: three of them had advanced superficial chronic gastritis (grade II), five had marked chronic gastritis with partial atrophy (grade III), and six had chronic gastritis with total atrophy in which intestinal metaplasia was observed (grade IV) (Siebenmann, 1964; Hafter, 1965).

The secondary effects of this drug were explained to all the patients, each of whom gave written consent to this investigation. These patients did not present

Received for publication 19 September, 1972. any other pathology. As well as the clinical examination, the following laboratory tests were carried out at 15-day intervals: haemoglobin, red cell, white cell, and platelet counts, blood sugar, urea, prothrombin, bleeding and coagulation times, cholesterol, and also tests for liver function consisting of transaminases (GOT and GPT), alkaline phosphatase, leucinoaminopeptidase, glutamate dehydrogenase, and serum proteins by electrophoresis. The main purpose of having these laboratory checks performed was to investigate whether side effects were being caused by azathioprine. Each patient had a barium examination of the oesophagus, stomach, and duodenum.

Gastric secretion was obtained by continuous aspiration from a nasogastric tube, the position of the tube being checked radiologically. The volume was measured, the $p \mathrm{H}$ was determined by special indicator paper (Acilit, Merck), and the total acid was titrated with $\mathrm{OHNa}$ solution $1 / \mathrm{ION}$ using as indicator phenolphthalein $(1 \mathrm{ml}=1 \mathrm{~m}$-equiv/1); acid output was calculated as the total acid multiplied by the volume of gastric secretion obtained in one hour after the injection of histamine acid phosphate $0.04 \mathrm{mg} / \mathrm{kg}$. Gastric secretion was measured again for all the patients at intervals of two months.

Gastric biopsy was performed with Sielaf's suction biopsy tube ${ }^{1}$. The samples were taken under fluoroscopic control and this examination was also

${ }^{1}$ Richard Wolf GmbH Knittlingen/Württ, West Germany 
repeated every two months. The specimen was fixed for study by light microscope in $10 \%$ formalin and was stained with haematoxylin and eosin.

All the patients were given azathioprine ${ }^{1}$ in a dosage that varied between 50 and $100 \mathrm{mg}$ per day and for a period ranging from two and a half months to six months (Table I).

\section{Side Effects}

Only one patient developed side effects, with nausea and vomiting even after two months and had to stop treatment.

\section{Results}

The gastric acid output was measured for the 14 patients with chronic gastritis of varying degrees of intensity, before, during, and after the administration of azathioprine (Table I). There was an improvement of more than $3 \mathrm{~m}$-equiv $/ 1 / \mathrm{h}$ in two of the three cases of advanced superficial chronic gastritis (grade

${ }^{1}$ IMURAN-Burroughs Wellcome \& Co.

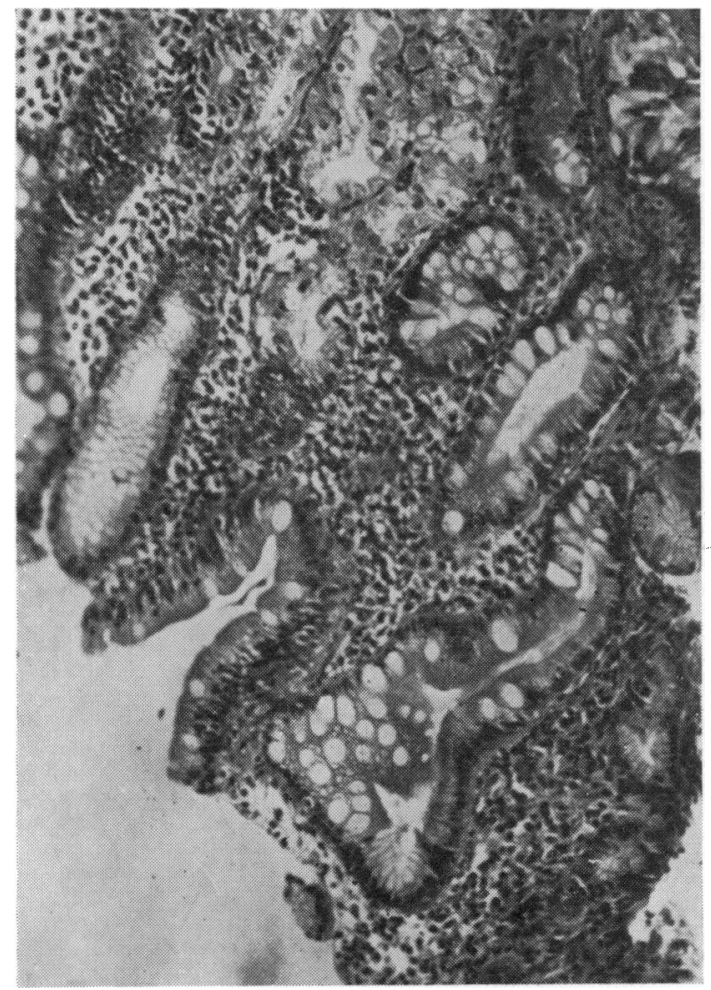

Fig. 1 Pac. J. L., 27-year-old patient, chronic gastritis with total atrophy and intestinal metaplasia before administration of azathioprine.

\begin{tabular}{|c|c|c|c|c|c|c|c|}
\hline \multirow[t]{2}{*}{ Name } & \multirow[t]{2}{*}{ Sex } & \multirow[t]{2}{*}{ Age } & \multirow[t]{2}{*}{$\begin{array}{l}\text { Treatment } \\
(m t h)\end{array}$} & \multicolumn{2}{|c|}{$\begin{array}{l}\text { Histopathology } \\
\text { Grading }\end{array}$} & \multicolumn{2}{|c|}{$\begin{array}{l}\text { Acid Output } \\
\text { (m-equiv/l) }\end{array}$} \\
\hline & & & & Before & After & Before & After \\
\hline G. de C. & $\mathbf{F}$ & 60 & 5 & II & II & $3 \cdot 4$ & $4 \cdot 0$ \\
\hline T. de T. & $\mathbf{F}$ & 49 & $2 \frac{1}{2}$ & II & II & $1 \cdot 8$ & $5 \cdot 8$ \\
\hline M. de L. & $\mathbf{F}$ & 57 & $2 \frac{1}{2}$ & II & II & $5 \cdot 4$ & 14.9 \\
\hline E. de M. & $\mathbf{F}$ & 48 & 6 & III & II & $0 \cdot 1$ & $0 \cdot 3$ \\
\hline V. de L. & $\mathbf{F}$ & 71 & 4 & III & II & $4 \cdot 3$ & $5 \cdot 4$ \\
\hline V.P. & $\mathbf{M}$ & 59 & 4 & III & III & $7 \cdot 4$ & $8 \cdot 1$ \\
\hline M.A. & $\mathbf{M}$ & 29 & 3 & III & II & $0 \cdot 2$ & $8 \cdot 2$ \\
\hline J. del R. & $\mathbf{M}$ & 51 & 5 & III & II & $6 \cdot 4$ & $18 \cdot 0$ \\
\hline M. de G. & $\mathbf{F}$ & 52 & 6 & IV & III & 0.0 & 0.1 \\
\hline T. de L. & $\mathbf{F}$ & 63 & 6 & IV & IV & $0 \cdot 3$ & 0.2 \\
\hline A. de T. & $\mathbf{F}$ & 51 & 6 & IV & III & 0.8 & 0.8 \\
\hline C.T. & $\mathbf{M}$ & 30 & 5 & IV & II & 0.4 & $0 \cdot 5$ \\
\hline G. de H. & $\mathbf{F}$ & 47 & 3 & IV & $\mathbf{N}$ & $4 \cdot 1$ & 14 \\
\hline J.L. & $\mathbf{M}$ & 27 & 5 & IV & $\mathbf{N}$ & $2 \cdot 5$ & $15 \cdot 6$ \\
\hline
\end{tabular}

Table I Effect of azathioprine on gastric mucosal histology and acid secretion in 14 patients with chronic gastritis

II), in two of the five patients with marked chronic gastritis with partial atrophy (grade III), and in two of the six cases of chronic gastritis with total atrophy (grade IV). If we consider the findings before and

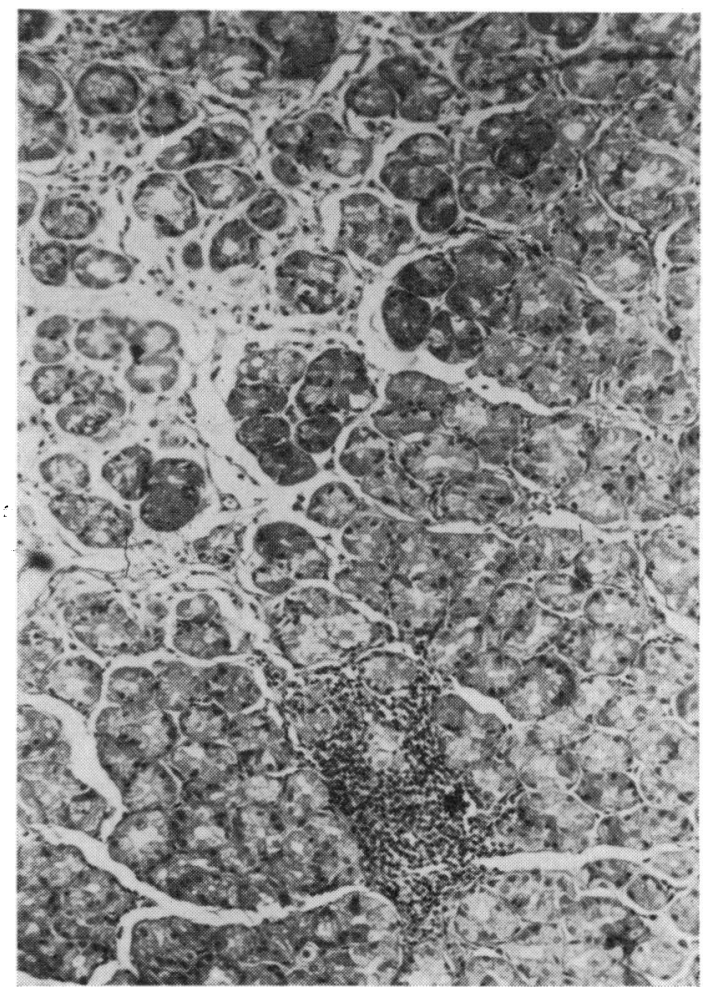

Fig. 2 The same patient six months after the administration of azathioprine, showing completely normal gastric mucosa. 


\begin{tabular}{|c|c|c|c|c|c|c|c|c|}
\hline \multicolumn{8}{|c|}{ Chronic Gastritis } & \multirow[t]{3}{*}{ Confidence Limits } \\
\hline \multicolumn{4}{|c|}{ Before Biopsy } & \multicolumn{4}{|c|}{ After Biopsy } & \\
\hline Normal & Grade II & Grade III & Grade IV & Normal & Grade II & Grade III & Grade IV & \\
\hline 0 & 0 & 0 & 2 & $\mathbf{0}$ & $\mathbf{0}$ & $\mathbf{0}$ & 0 & - \\
\hline 0 & 3 & 4 & 1 & $\mathbf{0}$ & 3 & 0 & 0 & $0.00-0.63$ \\
\hline 0 & 0 & 1 & 2 & $\mathbf{0}$ & 4 & 1 & $\mathbf{0}$ & $0.34-0.99$ \\
\hline 0 & 0 & 0 & 1 & 2 & 1 & 2 & 1 & $0.40-0.99$ \\
\hline
\end{tabular}

Table II Results of gastric biopsy in 14 patients treated with azathioprine

after treatment independently of the initial degree of severity, we find an average change of $4 \cdot 2$, with an estimated standard deviation $s(\bar{x})=1 \cdot 313$, which is significant even at the 0.01 significance level.

The gastric biopsies performed on the 14 patients before, during, and after the administration of azathioprine showed that of the five patients with chronic gastritis with partial atrophy (grade III) in one there was no evidence of any improvement, whilst in the other four glandular regeneration and a decrease in lymphoplasmocyte infiltration were observed, with the consequent improvement to grade II (advanced superficial chronic gastritis), and of the six cases of chronic gastritis with total atrophy (grade IV) in five the intestinal metaplasia disappeared, in two of these the gastric mucosa becoming normal (Figs. 1-2), in one to advanced superficial chronic gastritis (grade II), in two to chronic gastritis with partial atrophy (grade III), whilst in one case exactly the same picture was maintained (Table II). In Table II we give 0.95 confidence limits (Crow, 1956) for the proportion of patients who showed improvement after treatment for each initial grade. If we consider the cases as a whole such confidence limits would be $0 \cdot 37-0 \cdot 85$.

We thank Burroughs Wellcome \& Co. for the generous supply of azathioprine tablets used in this trial.

We are grateful to Luis Fornero, of the Institute de
Estadística Matemática, Fac de C Económicas, UNC, for his assistance in the statistical analysis of the results.

\section{References}

Ardeman, S., and Chanarin, I. (1965). Steroids and Addisonian pernicious anemia. New Engl. J. Med., 273, 1352-1355.

Crow, E. L. (1956). Confidence intervals for a proportion. Biometrika, 43, 423-435.

Doig, A., Girdwood, R. H., Duthie, J. J. R., and Knox, J. E. D. (1957) Response of megaloblastic anemia to prednisolone. Lancet, 2 , 966-972.

Fisher, J. M., Mackay, I. R., Taylor, K. B., and Ungar, B. (1967). An immunological study of categories of gastritis. Lancet 1, 176-180.

Fisher, J. M., Rees, C., and Taylor, K. B. (1965). Antibodies in gastric juice. Science, 150, 1467-1469.

Glass, G. B. J. (1970). In Progreso en Gastroenterologia, Vol. I, p. 1. Scientifica Medica.

Hafter, E. (1965). Praktische Gastroenterologie, 3rd. ed., pp. 164. Thieme, Stuttgart.

Hausamen, T. U., Halcrow, D. A., and Taylor, K. B. (1969). Biological effects of gastrointestinal antibodies. III. The effects of heterologous and autoantibodies on desoxyribonucleic acid synthesis in the stomach and colon of guinea pigs and rabbits. Gastroenterology, 56, 1071-1077.

Hennes, A. R., Sevellius, H., Llewellyn, T., Woods, A. H., Joel, W. and Wolf, S. (1960). Experimental production of atrophic gastritis by a presumably immunogenic mechanism. (Abstr.) J. Lab. clin. Med., 56, 826-827.

Ir vine, W. J. (1965). Immunologic aspects of pernicious anemia. New Engl. J. Med., 273, 432-438.

Jeffries, G. H., Todd, J. E., and Sleisenger, M. H. (1966). The effect of prednisolone on gastric mucosal histology, gastric secretion, and vitamin $B_{12}$ absorption in patients with pernicious anemia. J. clin. Invest., 45, 803-812.

Kristensen, H. P., and Friis, T. (1960). Effect of prednisone on $\mathbf{B}_{12}$ absorption in pernicious anaemia. Acta med. scand., 166, 249-254.

Kristensen, H. P., and Friis, T. (1962). The mechanism of prednisone effect upon $B_{12}$ absorption in pernicious anemia. Acta med. scand., 168, 457-459. 